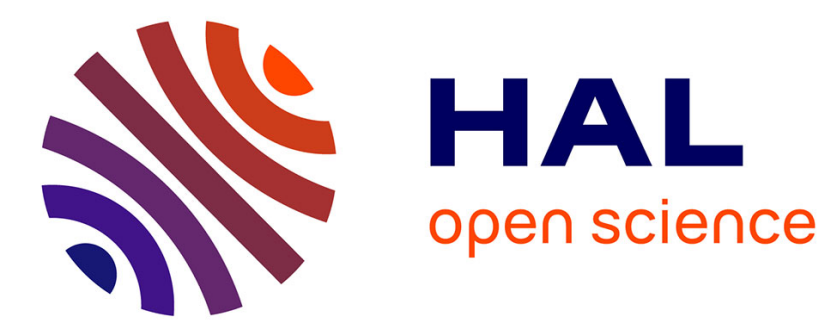

\title{
Field Data vs. Theoretical Model to Quantify Drilling Efficiency and Disruption
}

C. Putot, Ph. Perreau, A. Constantinescu

\section{To cite this version:}

C. Putot, Ph. Perreau, A. Constantinescu. Field Data vs. Theoretical Model to Quantify Drilling Efficiency and Disruption. SPE Drilling and Completion, 2000, 15, pp.118-124. 10.2118/50579-MS . hal-00111303

\section{HAL Id: hal-00111303 https://hal.science/hal-00111303}

Submitted on 4 Sep 2019

HAL is a multi-disciplinary open access archive for the deposit and dissemination of scientific research documents, whether they are published or not. The documents may come from teaching and research institutions in France or abroad, or from public or private research centers.
L'archive ouverte pluridisciplinaire HAL, est destinée au dépôt et à la diffusion de documents scientifiques de niveau recherche, publiés ou non, émanant des établissements d'enseignement et de recherche français ou étrangers, des laboratoires publics ou privés. 


\title{
Field Data vs. Theoretical Model to Quantify Drilling Efficiency and Disruption
}

\author{
C. J. M. Putot, SPE, P. J. Perreau, SPE, Institut Français du Pétrole and \\ A. Constantinescu, ASME, Ecole Polytechnique
}

\begin{abstract}
Mechanical and kinematics data at the bit have been collected during drilling operations and organized to identify optimal drilling efficiency. Transitional conditions towards abnormal behavior have been distinguished. Normal drilling is usually characterized by regular linear relationships between global control variables at the bit, which approximately correspond to an up scaling of a local Mohr Coulomb type failure mechanism of the rock. Most of our experimental data confirm this classical disposition. However, considerable departure from these relationships is noted, especially when there is BHA resonance or when there is partial balling at the bit. The field tests presented here allows us to verify classical theory and to draw up new guidelines for behavior in nonoptimal or dangerous, evolving operating conditions, such as those that occur under poor cleaning conditions. The main features of a mechanical structuring model involving transition towards low efficiency conditions are presented, and it is shown how this model confirms our interpretation of field data. The model couples the drillability of rock and the general dynamics of the bit in an original and synthetic way. It makes it possible to understand and test the sensitivity of bit response to variables such as "weight on hook", torque on the drillstring and flow rate of the fluid.
\end{abstract}

\section{Introduction}

Common perception of drilling efficiency. The idea of combining the specific energy associated with rock crushing and the energy from hydraulics in order to achieve a synthetic view of bit efficiency in soft rock is not new. Refs. 1 and 2 have defined semi-empirical relationships which take into account the tendency for the rate of penetration to level off when weight on the bit increases beyond normal values. These schemes have been verified through numerous tests but, as they cover ordinary conditions, cannot describe conditions like transients to balling, for example.

Meanwhile, some experts think that it is time for a new perception of hydraulics. According to Warren (Ref. 3), "Generally, when people talk about bit hydraulics, they are referring to some measure of flow rate and pressure drop, but those factors cannot be considered independent of the particular bit design. The major issue is that the bit should be designed and operated in such a way that drilled cuttings do not impede drilling efficiency. When drilling in soft rocks, preventing bit and cutter balling is a primary concern."

Drilling conditions. It appears from these considerations that two kinds of drilling conditions must be distinguished:

1. Those for which a slight perturbation of operating parameters will not significantly modify the drilling conditions. These drilling conditions will be considered as stable, and they do not significantly evolve in time. They correspond to rather efficient conditions for which vibration is low. An optimum may be distinguished.

2. On the other hand, transitions towards abnormal conditions may be observed when control variables are poorly chosen. Among these are:

2.1. High levels of vibration and correspondingly low rates of penetration, such as those that are observed with poorly designed bits when crossing hard and abrasive formations (Fig. 1, bottom part, for axial vibrations). The art of the designer is to introduce elements that reduce both the severity and sharpness of vibration peaks and the range of operating conditions where these detrimental conditions appear. The strategy, when conducting drilling operations, is to find ways to escape from these conditions either by reducing rotary speed or decreasing weight on the bit.

2.2. Low efficiency associated with balling mechanisms, principally when drilling soft rocks, also characterized by very low penetration rates (Refs. 4 through 
6). This phenomenon generally appears after a temporary increase in performance with excessive generation of crushed material and, consequently, sudden saturation of the cutting head (see for example Fig. 14 of Ref. 4). Excessive weight on the bit or rotation speed are generally at the origin of this disruption. Certain forms of balling may be irreversible. We will concentrate on this second type of disruption.

Numerical Analysis and Validation. Considering that drillability and dynamics are correlated, an assertion that has often been made, but that has yet to be practically applied, it is useful to demonstrate the complementary roles of bit dynamics and drillability with a model that covers unusual conditions. This model is intended to show the effects of mixed cutting and cleaning conditions on bit dynamics. Among these are some special forms of bit bouncing (Fig. 1) that occur within soft rocks when the cleaning flow of crushed rock is plugged. Brett (Ref. 7), among possible causes of angular excitations, cites bad cleaning conditions as possible candidates for stick-slip. Our model, called CUTCLEAN, dynamically couples axial and rotational degrees of freedom at the bit with a concentration variable at the bit in a very simple and synthetic way. The forces and moments of various origins encountered at the bit explicitly depend on these three state variables. The solution expresses the evolution in time of these three state variables, for a convenient choice of the control variables $\mathrm{W}, \mathrm{N}, \mathrm{Q}$.

The second step of our approach is to verify the expressions for forces and moments included in the model using examples taken from field cases. The main difficulty with field data is the assumption, which is rarely fully justified, that rock is homogeneous. The way to overcome this difficulty is to use stabilized sequences of drilling behavior that are, when possible, sufficiently long to ensure stabilization of the process, but not long enough to risk crossing a geological transition. Nevertheless, it is impossible to eliminate variability on a centimeter scale.

The validation examples are of two types. The usual way is simply to describe systematically the global parameter and response of the drilling system and to observe the effects as a function of time, under the control of the operator. Stable behavior can be reversible, whereas some types of balling are not. A more systematic and rational way to observe response behavior is to carry out specially designed experiments with programmed sequences of weight on bit, rate of rotation and hydraulics. The two types of experimental data have been carefully collected and combined to create a "representative" state.

\section{Experimental Evidence of Three Typical Regimes}

Three kinds of typical behavior have been observed and classified (Fig. 2) (An excessive level of vibration associated with hard rock interaction is disregarded).

Type I: Normal case. Interpretation of control parameters $R_{D}$ and $T_{D}$ according to a classical representation derived from Warren (Ref. 8) and proposed by Falconer (Ref. 9) for a Tricone bit (extended to PDC). The dimensionless torque, $T_{D}$, plotted as a function of reduced rate of penetration, $\sqrt{ } R_{D_{1}}$ leads to a linear relationship (Fig. 3). The distribution of points reflects the intrinsic variability of conditions imposed by the natural variation of rock properties, even when the driller does not modify control parameters. Small-scale properties induce slight perturbations of parameters. The ordinate $T_{D}$ represents (Pessier and Fear, Ref. 10) the "friction coefficient" of the bit, insofar as the failure mechanism might be comparable to friction. A rapid calculation suggested by the authors shows that the actual friction coefficient $\mathrm{m}$ is three times that value. Some fundamental experimental research (Scholz, Ref. 11) relates this coefficient to rock properties and normal stress. This evaluation corresponds to normal behavior and has a secondary dependence on surface roughness and relative velocity.

Orders of magnitude. The effects described above are quite difficult to quantify. Nevertheless, the order of magnitude $\left(m=0.6, T_{D}=0.2\right)$ is in accordance with the observed values. These are lower for Tricones ( about 0.15) than for PDC's ( about 0.3 ), and this observation is related to the fact that the kinematics of the bit types are rather different. The rolling movement with relatively low shearing and "friction" for Tricones is in contrast with the high shearing interaction for PDC's.

Some possible justification of variations. Whether the straight line that represents dimensionless torque $T_{D}$ as a function of the dimensionless rate of penetration $\sqrt{ } R_{D}$, which varies monotonically with weight on bit in this case, increases or decreases could depend on hydraulics. Detournay's (Ref. 12) analytical expression seems to confirm this assumption for PDC's. With this interpretation in mind, the direction of the slope is obviously related to the friction parameter, which could logically increase with decreasing hydraulic efficiency. This could be the reason why we observe negative slope when hydraulics are unfavorable. The common feature of this class of behavior is the moderate value of $T_{D}$. From the "rock mechanics" point of view, this behavior calls to mind a possible saturation of admissible shear as confinement increases (hydrostatic stress state), which has been demonstrated by different authors. Positive and negative slopes could be two facets of the same failure characteristic (increasing admissible shearing stress for moderate mean stress and decreasing for higher values).

Type II: Slow balling with low weight on bit. We refer to this type of behavior when excess $T_{D}$ is observed, with relatively low weight on bit. This behavior is referred to by Falconer to justify significant departure from the normal failure rule and it may be due to failure of a seal or a roller bearing (cone locking). In that case, the teeth of the locked cone bite into the formation very aggressively, resulting in a significant jump in downhole torque. Our own further 
interpretation is that this kind of behavior is not always irreversible and could also be linked to polluting the cutting front with very fine particles. This might result from a special kind of packing mechanism at the front caused by too little weight on bit and involving very small rock cuttings and generating high relative torque, probably resulting in an inefficient abrasive mechanism (below the threshold of normal cutting). See Ref. 10, Fig. 6 "bottom balling with buffer of fines; clean and contaminated bearing". It is quite difficult to distinguish between mechanical inefficiency and pollution by very small particles.

Type III: Rapid balling with excess weight on bit. This behavior, with simultaneous low $R_{D}$ and low $T_{D}$ is, according to Falconer, symptomatic of balling mechanisms or drilling very compact, low porosity rocks. These two elements are mutually exclusive and therefore easy to separate. Concentrating on the balling mechanism, it is important to stress that, as with type II and anticipating subsequent interpretation, such piling up of cuttings does happen with excessive weight on bit. We will see below the mathematical significance of types II and III. Table 1 sums up the main characteristics of the three mechanisms.

\section{Major Features of CUTCLEAN Models \\ General presentation of specific models coupling dynamics and drillability}

First preliminary version, quasi-static (CUTCLEAN) Ref. 13 (Fig. 4 and Fig. 5): It defines, using hydrodynamics, equations that show the time evolution of general balling conditions at the cutting front. It shows critical regimes (Fig. 5) as a function of the controlling parameters weight on bit, rotary speed and flow intensity. Excessive weights (regime 5) lead rapidly to balling with accumulation of coarse material whereas insufficient weights (regime 1) induce slow, progressive pollution with small particles and contribute as well to an inefficient regime. This, too, could be defined as balling, making the description of the mechanical threshold, which is usually associated with abrasion and wearing mechanisms, more comprehensive by adding a hydraulic dimension .

Bit dynamics when considering the concentration of cuttings at the cutting front (CUTCLEAN 2) Ref. 14: In a simplified version, for which a numerical simulation exists, two dynamic state variables have been defined with axial and circumferential degrees of freedom and one to describe the concentration of solids. The solution of the system of differential equations coupling these state variables is as much a problem in dynamics as it is in describing this concentration. As will be seen, the influence of initial conditions, the gradient of independent loading control parameters weight and torque, have been studied. The advantages of this approach over the quasi-static model are significant, as it explains the influence of bit dynamics on the evolution of concentration and is a contribution to the understanding of drilling system dynamics in balling problems (See, for example, Fig. A-1 through A-4 described in the Appendix).

Mechanical structure of the simplified version CUTCLEAN 2. The model proposed below is based on:

(i) Interpretation and quantification of the forces generated at the bit by cutting, sliding friction and cleaning mechanisms.

(ii) Compatibility equations of forces and moment components expressed in a dynamic form.

(iii) Balance equations concerning "conservation" (production and evacuation) of rock cuttings and mud flow.

The model relies on ordinary differential equations and is described elsewhere in detail (Ref. 14). Its major features are outlined in the appendix. Drilling is essentially controlled by the three parameters weight on bit, rotary speed and hydraulic energy. In the simplified version of our model, three state variables are naturally introduced and matched with these control parameters. They are $\xi$, axial position of the bit; $\theta$, angular position, and $l$, level of cuttings at the head. These equations are:

$\frac{d l}{d t}=S_{C} \frac{d \xi}{d t}-x Q_{M}$

$M \frac{d^{2} \xi}{d t^{2}}=M g-W_{M}+K_{\xi} \xi_{0}-W_{H}-W_{C}-W_{F}$

$J \frac{d^{2} \theta}{d t^{2}}+V_{\theta} \frac{d \theta}{d t}+K_{\theta} \theta=K_{\theta} \theta_{0}-T_{C}-T_{F}$

(1c)

Solving evolution equations numerically. The practical numerical application involves the following variables: $l$, the volume of cuttings at the front, $r=M \frac{d \xi}{d t}$, the rate of penetration, $v=J \frac{d \theta}{d t}$, the instantaneous rotary speed at the bit. A general form of the balance equations is written (Fig.4):

$$
\frac{d l}{d t}=B(t, l, r, v)=B^{+}(r, v)-B^{-}(l, r, v)
$$

$$
\frac{d r}{d t}=W(t, l, r, v)=W^{+}(t)-W^{-}(l, r, v)
$$




$$
\frac{d v}{d t}=T(t, l, r, v)=T^{+}(t)-T^{-}(l, r, v)
$$

Here, $B^{+}, B, W^{+}, W, T^{+}, T$ are respectively the positive and negative parts of the balance of mass, weight and torque functions. The structure of the functions has been chosen so that conformity to general observations is qualitatively ensured. Experimental results for balling phenomena are scarce, so systematic rules for determining $\mathrm{W}_{\mathrm{H}}$ must be coherent with general intuition as much as with data borrowed from diamond bit studies, for which pump-off effects are important, even in the absence of balling (see, for example, Refs. 15 and 16). In parallel, a phenomenological analytical model, involving elementary forces on the scale of the cutting, has been developed in detail. This work was carried out when building the quasi-static CUTCLEAN model, in order to describe more precisely the hydrodynamic action of mud on particles on the basis of Morison equations. This formulation is inspired by the work of Eronini (Ref. 17). See Fig. 5a , b and $\mathbf{c}$ for a brief summary of results using the quasi-static model CUTCLEAN. Later on, when building CUTCLEAN 2, a global mathematical expression has been applied to the results in order to simplify the writing. The general form of the model brings out the importance of the coupling between dynamic equations and mass balance equations, translated by the explicit dependence of weight and torque on $l$.

Criteria for balling: The criterion for balling could be either $r \rightarrow 0$ or, $l \rightarrow l_{\text {critical. }}$. The results are in agreement with experimental facts. For a constant control parameter $W^{+}$, we notice three regimes (see Fig. A-1 and A-2, for example):

- For lower and higher values of $W^{+}$, the drilling system plugs up $(r \rightarrow 0)$ with respectively small and large values of cutting bed parameter $l$.

- For intermediate values of $W^{+}$, the dynamic system reaches an equilibrium point or a limit cycle. Transition between these regimes is sudden and occurs when the trajectory reaches a bifurcation point

$$
B(r, l)=W(r, l)=0 \text {. }
$$

Important remarks: The rate at which the weight on bit increases to a given final value may influence whether a possible equilibrium state occurs, as may initial conditions. For a stabilized level control variable, several types of accumulation points can be distinguished (see Figs. A-3 and A-4, for example):

- On the $r=0$ axis, reaching balling state.

- On the $l=0$ axis, when $B(r, l)<0$, conditions for which excess cleaning possibilities exist.

- On $B(r, l)=0$, which corresponds to singular points of the dynamic system.

\section{Interpretation of field data}

Specific tests while drilling have been conducted on two Gaz de France well sites. One goal was to verify theoretical models that describe some of the typical vibration modes that occur during drilling operations. A specific data acquisition system, Trafor (Ref. 18), was used for this purpose. The operation was conducted with a $121 / 4$ " Tricone bit, in rather soft formations, prone to balling, for one site, and hard rock for the other.

General remarks. Field data show:

(i) The relevance of the classic linear type I representation, in most cases.

(ii) The frequent occurrence of sequences for which the representation no longer applies. The general form of the results obtained with CUTCLEAN is used to confirm information collected from field data.

The overall conclusion of this work is the fact that type II is linked to slow accumulation of fine particles generated by ineffective and insufficient weight, whereas type III is connected with balling obtained by rapid piling up of coarse material produced by excessive weight. Types II and III are linked respectively to high and low values of non dimensional torque, which is similar to a coefficient of friction between the bit and the formation. According to Pessier and Fear (Ref. 10) , the most critical reason for the destruction of roller cone bits is bearing or seal failures. It is associated, and occurs. simultaneously, with an increase in the coefficient of friction, $T_{D}$, between the bit and the bad bearing (from $0.2-0.25$ reaching 0.55), higher than normal values for drilling efficiency but relatively low values of weight on bit. The bit gradually becomes a low efficiency drag bit as is demonstrated by the trend toward reduced observation variables $E_{S}, m$ or, equivalently, $T_{D}, R_{D}$.

Extrapolation of field data with the help of a systematic program. A grid of independent pairs of the input parameters rotary speed, $\mathrm{N}$, and weight on bit, $\mathrm{W}$, is formed for testing on the well site and the rate of penetration is observed for each (Fig. 6). Hydraulics has been modified in a limited way with no significant effect. Sequences have been carried out for a sufficient duration to ensure stabilization of the process and representative values of the control and response parameters.

Considering $\mathrm{R}$ (rate of propagation) as a function of $\mathrm{N}$ (rotary speed) for 4 levels of $\mathrm{W}$ (weight on bit) (30, 50, 70, 90 $\mathrm{kN}$ ), a very clear trend to performance saturation appears for low weights, which agrees very well with results previously described for CUTCLEAN calculations (weight threshold with a hydraulic correction). More intuitive and well known is balling that occurs with high weights, which seems, in our case, to appear in the vicinity of $\mathrm{W}=100 \mathrm{kN}$ and $\mathrm{N}=100 \mathrm{rpm}$ (Fig. 9).

Since weight, $\mathrm{W}$, and rotary speed, $\mathrm{N}$, are the two engines for producing rock cuttings, it is normal that, for given 
hydraulics and extension of the cutting head (corresponding to a potential mass flux), a saturation point is reached when upper bounds of couples $\left(\mathrm{W}^{*}, \mathrm{~N}^{*}\right)$, characteristics of collapsing performances, are observed. This saturation is observed with $\mathrm{R}(\mathrm{N})$ curves for constant $\mathrm{W}$ as well as with $\mathrm{R}(\mathrm{W})$ curves for constant $\mathrm{N}$.

Investigations for non vanishing values of $R$ are also of undeniable interest and are now considered.

Extrapolation induced by CUTCLEAN analysis: The synthesis presented here is based upon compatibility, for given hydraulics, of two families (sets) of parametrically indexed curves (Fig. 7):

\section{(1) $R(N)$, parameter $W$}

(2) $\mathrm{R}(\mathrm{W})$, parameter $\mathrm{N}$

- Set of curves $R(N)$, parameter W: A careful study of gradual modification of set (1) with parameter W can be summarized as follows:

(i) For low weights on bit, typically 20 to $40 \mathrm{kN}$, we generally observe low efficiency, but with a maximum of performance for a relatively low rotary speed (50 to 75 rpm). Performance collapses at about 100-150 rpm, perhaps due to a balling mechanism with fine particles, possibly connected with seal bearing deterioration, as Pessier and Fear seem to propose. The prototype for this regime is sequence A, case 870 (Fig.8), for which an unusual increase of $T_{D}$ is observed when weight on bit decreases and there is simultaneously evidence for reduced efficiency, R.

(ii) For high weights on bit, typically 90 to $100 \mathrm{kN}$, we observe good efficiency, but for a range of $\mathrm{N}$ values decreasing progressively with increasing weight on bit, $\mathrm{W}$. It appears to be symmetric with behavior (i). In this case, a balling mechanism provides an upper limit to rotary speeds. Case 867, Sequence A (Fig. 9) is representative, showing a balling tendency for a rotary speed around 100 rpm.

(iii) For intermediate weights on bit, typically 50 to $80 \mathrm{kN}$, the acceptable range of rotary speeds is wider than in the preceding limit cases. Efficiency continues to be significant. This average value of weight will offer a maximum margin of safety without penalizing performance.

- Set of curves $R(W)$, parameter $N$ : The gradual modification of family (2) with parameter $\mathrm{N}$ can be summarized as follows:

(i) Except for very low values of N, the acceptable domain of weight on bit increases considerably with decreasing rotary speed.

(ii) The higher rotary speed, $\mathrm{N}$, the more sudden and earlier the onset of balling with excessive weight on bit.

(iii) The hydraulic threshold described above is hardly noticeable for reduced rotary speeds, but becomes apparent at about $\mathrm{N}=100 \mathrm{rpm}$ and is $30 \mathrm{kN}$ for that speed.

(iv) Maximal estimated efficiency is obtained for these hydraulics over a large range of control parameters $\mathrm{W}$ and $\mathrm{N}$. Special care must be taken for those values close to the "cliff" at the edge of the large "shelf" of maxima, which indicate a tendency towards balling.

(v) The choice of $\mathrm{N}$ values seems to be relatively unimportant in the upper range. On the other hand, once this choice is made, it is imperative to control $\mathrm{W}$, in order to avoid balling.

\section{Remark concerning the CUTCLEAN model:} CUTCLEAN is a general simplified model for which only full balling is assumed. Consequently, the phenomena described by this code are usually more extreme than in real cases, where partial plugging of cutters is a more realistic hypothesis.

\section{Summary of field testing: Interpretation and representative types of behavior}

These tests:

1. Confirm the classical Falconer representation, which is linear in both the dimensionless rate of progression and the specific energy (behavior type I).

2. Show the existence of numerous sequences where this linear rule is not valid, either because the nature of the rock has radically changed and induced a different failure mode (adjusting t/s defines other Falconer-type lines, higher for porous, lower for compact rocks), or because some type of disruption has occurred, either due to drilling hard rock, where there is bit bouncing or whirling, with a large amount of dissipated energy that is not involved in drilling, or to mechanisms for clearing rock cuttings, which phenomena also have a dynamic component. At this point, two types of situations may occur:

- Type II behavior: When hydraulics is limited but rate of penetration is not too low, (Warren leveling off curves) the behavior, in Falconer's variable space, seems to translate into high negative slope lines. In the closely related Detournay coordinate system, more specific to PDC's, this type of behavior is related to increased friction. It is physically compatible, in the spirit of the model, with the idea of increased dissipation, which here finds its origin in viscous flow pressure losses.

- Type III behavior: When behavior tends towards balling by excess weight, the evolution can no longer be represented by type II straight lines. The operating point reaches very low values of $R_{D}$ and $T_{D}$, as has been observed by other authors, and which we effectively confirm with our tests.

Balling with excess weight (type III) is a rather well known phenomenon for which a sound interpretation exists. Its sudden onset has been confirmed by field and laboratory 
experience (under our test conditions, $\mathrm{W}=100 \mathrm{kN}$ and $\mathrm{N}=100$ rpm)

Balling with insufficient weight (type II) is less intuitive and tends to appear in combination with threshold effects associated with inefficient cutting (see, for example, Glowka, Ref. 19). Its existence has been mathematically proven, using CUTCLEAN (Ref. 13), for conventional hydrodynamic hypotheses concerning particles of assumed granulometry. However, these physical relationships must be confirmed in order to validate the result. This effect has been identified during tests which show performance saturation for low weights (30 and $40 \mathrm{kN}$ ) and relatively high velocities (100 $\mathrm{rpm})$.

After extrapolating and fitting the data, a representative case, which can act as a reference for a semi-quantitative but instructive discussion of drilling efficiency, has been formulated. The data analysis is an indirect step in validating the mathematical functions, in terms of $W_{C}, W_{F}, W_{H}$, introduced by CUTCLEAN.

Consequences for the driller's response to balling. Distributing sets of characteristics $\mathrm{R}(\mathrm{N})$, for parameter $\mathrm{W}$ or $\mathrm{R}(\mathrm{W})$, for parameter $\mathrm{N}$, could be useful to drillers. It could give them quantitative indications of the response of the drilling system in the neighborhood of a selected operating point. Conversely, this map could allow them, since it provides all the useful information, to modify this point, if necessary.

\section{Nomenclature}

\section{Global parameters}

$\mathrm{D}=$ bit diameter

$\mathrm{W}, \mathrm{WOB}=$ weight on bit

$\mathrm{T}_{\mathrm{D}}=\mathrm{T} / \mathrm{WD}=$ non dimensional torque

$\mathrm{T}, \mathrm{TOB}=$ torque on bit

$\mathrm{N}=$ rotary speed

$\mathrm{Q}=$ hydraulics

$\mathrm{R}, \mathrm{ROP}=$ rate of penetration

$R_{D}=R / N D=$ non dimensional rate of penetration

$\mathrm{E}_{\mathrm{S}}=$ efficiency

$\mathrm{m}=$ friction coefficient

\section{Parameters and variables}

\section{specific to the numerical model}

$\xi=$ axial coordinate

$\theta=$ angular coordinate

$l$ = cutting accumulation

$\mathrm{h}=$ residual mud layer

$\delta=$ equivalent depth of cut

$\mathrm{v}=$ angular velocity

$\mathrm{r}=$ rate of penetration

$\mathbf{M}=$ mass

$\mathrm{J}=$ inertia term (rotational)

$\mathrm{V}=$ viscous term (rotational)
$\mathrm{K}=$ rigidity term (rotational)

$\mathrm{B}=$ balance of solid mass

\section{Subscripts}

$$
\begin{aligned}
& D=\text { dimensionless }\left(T_{D} \text { and } R_{D}\right) \\
& M=\text { mass } \\
& C=\text { cutting force or moment } \\
& F=\text { friction force or moment } \\
& H=\text { hydraulic force }
\end{aligned}
$$

\section{Acknowledgments}

We thank our colleagues Maurice Boutéca and Jean Guesnon for valuable discussions on the interpretation of the tests, Isabelle King for valuable improvement of CUTCLEAN quasi-static model.

The authors would like to give credit to the field engineers who have made the data acquisition Trafor a success at Gaz de France well sites. They also wish to thank the management of Géoservices for permission to present the paper. The helpful discussions and comments of Hédi Sellami and Christophe Simon of the Centre de Géotechnique et Exploitation du Sous-Sol of the Ecole des Mines de Paris have been appreciated.

The authors wish to acknowledge the Fonds de Soutien des Hydrocarbures for sponsoring the program.

\section{References}

1. Wardlaw, H. W. R.: "Optimization of Rotary Drilling Parameters", thesis report, Texas University, 1971.

2. Warren, T. M.: "Penetration-Rate Performance of Rotary Drilling Parameters", SPE Drilling Engineering, March, 1987.

3. Fear, M. J., Knowlton, R. H., Meany, N. and Warren, T. M.: "Experts Discuss Drill-Bit Design, Field Performance", JPT, 100, February, 1995.

4. Hemphill, T. and Clark, R. K.: "Effects of PDC-Bit Selection and Mud Chemistry on Drilling Rates in Shale", SPE Drilling \& Completion, 176, September, 1994.

5. Cheatham, C. A. and Nahm, J. J.: "Bit Balling in WaterReactive Shale During Full-Scale Drilling Rate Tests", paper SPE 19926 presented at the 1990 IADC/SPE Drilling Conference in Houston, February 27-March 2, 1990.

6. Pessier, R. C., Fear M. J. and Wells M. R.: "Different Shales Dictate Fundamentally Different Strategies in Hydraulics, Bit Selection, and Operating Practices", paper SPE 28322 presented at the 1994 Annual Technical Conference and Exhibition in New Orleans, September 25-28, 1994.

7. Brett, J. F.: "The Genesis of Bit-Induced Torsional Drillstring Vibrations", SPE 21943, Amsterdam, 1991.

8. Warren T. M.: "Factors Affecting Torque for a Roller Cone Bit", Journal of Petroleum Technology, 1984. 
9. Falconer, I. G., Burgess T. M. and Sheppard, M. C.: "Separating Bit and Lithology Effects from Mechanical Data", IADC, SPE 17191 Drilling Conference, Dallas, 1988.

10. Pessier, R. C. and Fear M. J.: "Quantifying Common Drilling Problems With Mechanical Specific Energy and a Bit-Specific Coefficient of Sliding Friction", SPE 24584, Washington D. C., October 4-7, 1992.

11. Scholz C. H.: "The mechanics of earthquakes and faulting" Cambridge University Press, 1990.

12. Detournay E. and Defourny P.: "A Phenomenological Model for the Drilling Action of Drag Bit", Int. J. Rock. Min. Sci. \& Geomech. Abstr., Vol. 29, No 1, pp. 13-23, 1992.

13. Putot, C.: "Modèle de foration fondé sur le couplage de la destruction de la roche et d'évacuation des débris", Revue de l'IFP, vol. 50, $\mathrm{N}^{\circ} 4,1995$.

14. Putot, C. J. M. and Constantinescu, A.: "Modèle de foration fondé sur le couplage des effets d'évacuation des déblais et de coupe de la roche", Symposium SaintVenant, ENPC, Paris, 1997.

15. Warren T. M. and Winters, W. J.: "Laboratory Study of Diamond-Bit Hydraulic Lift" , SPE Drilling Engineering, August, 1986.

16. Warren T. M. and W. J. Winters, W. J.: "Field Application of Diamond-Bit Hydraulic Lift Principles", SPE Drilling Engineering, August, 1986.

17. Eronini, I. E., Somerton, W. H. and Auslander, D. M.: "A Dynamic Model for Rotary Rock Drilling" Journal of Energy Resources Technology, Vol. 104, p. 108, June, 1982.

18. Pavone D. R. and Desplans J. P.: "Application of Sampling Rate Downhole Measurements for Analysis and Cure of Stick-Slip in Drilling", presented at The SPE Annual Technical Conference and Exhibition, New Orleans, September, 1994.

19. Glowka D. A.: "Use of Single-Cutter Data in the Analysis of PDC Bit Designs: Part 1- Development of a PDC Cutting Force Model. Part 2 - Development and Use of the PDCWEAR Computer Code", JPT, August, 1989.

\section{Appendix - Drilling Model Based on Balance of Mass, Forces and Moments, Taking Account of Coupled Effects. Variables}

In order to optimize control of the operation and to predict balling, a "drilling model" has been developed, that includes large scale phenomena, such as the dynamics of the drillstring, and small scale phenomena, such as the rock cutting mechanism and the circulation of the cuttings. Different hypotheses have been formulated, and a numerical simulation in a simplified configuration that illustrates the responses of the system to different command schemes is presented.

In the most general case, we suppose that the position of the bit is characterized by the following variables:

$\xi[\mathrm{m}]$ - axial position of the bit.

$\theta[\mathrm{rad}]$ - angular position of the bit.

$h\left[\mathrm{~m}^{3}\right]$ - volume of current mud and cuttings flowing beneath the bit (open face volume).

$x$ [adim] - volume percentage of cuttings in the mud in circulation.

$l\left[\mathrm{~m}^{3}\right]$ - volume of cuttings, flowing around and beneath the bit.

$v_{R}\left[\mathrm{~ms}^{-1}\right]$ - velocity of the fluid at the collector channel exit.

With this choice of variables, we implicitly assume that:

1. The entire mud volume $(1-x) h$ is in circulation, that is, neither internal circulation in the bit nor mud losses in the rock.

2. Cuttings are shared between a "cuttings bed", $l$, remaining under the bit and a quantity $x h$ which will be expelled by the return area. Cutting particles and mud have the same velocity.

3. The bit is in permanent contact with the rock, which presupposes no bit bouncing.

4. The drillstring is rigid.

Note that $d \xi / d t$ and $d \theta / d t$ are identical to $R O P$ and $R P M$ values at the bit and that $\delta=d \xi / d \theta$ is the equivalent depth of cut.

\section{Equations}

- Solid mass balance (cuttings)

$$
\frac{d}{d t}[x h+l]=S_{c} \frac{d \xi}{d t}-x v_{R} S_{R}
$$

where $v_{R}$ and $S_{R}$ are respectively the velocity of the mud flow and the area at the exit. $V_{R} S_{R}$ is the flow of total mass: mud + cuttings. $S_{c}$ is the "cutting area", which characterizes the rate of solid mass generated for a rate of penetration $\mathrm{d} \xi / \mathrm{dt}$.

- Fluid mass balance (mud)

$$
\frac{d}{d t}[(1-x) h]=Q_{M}(t)-(1-x) v_{R} S_{R}
$$

where $Q_{M}(t)$ is the instantaneous mud flow given by the pumps, recorded at the bit.

- Interaction of cuttings with mud, the relationship describing the drag effect on the cuttings in mud flow

$$
\frac{d x}{d t}=f(h, l, x, v, \ldots)
$$

where $v$ is an average velocity of mud in the collector channels. The function, $f$, expresses, for a given state of the system, the ability of the mud to drag cuttings out.

- Force balance (equilibrium) in mud (simplified Navier Stokes equations) 
$\rho \frac{d v_{R}}{d t}=-\frac{\Delta p}{L}+\mu \frac{\Delta v}{L^{2}}$

where $\Delta p$ and $\Delta v$ are two given functions which characterize pressure and velocity losses at the bit and $\mathrm{L}$ is a characteristic length.

- Axial force balance (dynamic equilibrium)

$M \frac{d^{2} \xi}{d t^{2}}=M g-W_{M}+K_{\xi} \xi_{0}-W_{H}-W_{C}-W_{F}$

where $\mathrm{Mg}$ is the drillstring weight, $W_{H}, W_{C}, W_{F}$ represent respectively the hydraulic lift (pump off force), the cutting and the frictional components of true $W O B, W_{M}$ is the weight on hook, the part of the weight controlled by the driller with the brake and which will be considered as a given function of time.

- Torsional balance (dynamic equilibrium of moments)

$J \frac{d^{2} \theta}{d t^{2}}+V_{\theta} \frac{d \theta}{d t}+K_{\theta} \theta=K_{\theta} \theta_{0}-T_{C}-T_{F}$

where $J, V_{\theta}$ and $K_{\theta}$ are respectively rotational inertia, damping and stiffness characteristics, $T_{C}$ and $T_{F}$ represent respectively the torque components attributed to the cutting mechanism and that are involved in wear flat friction. $K_{\theta} \theta_{0}$ is the driving torque and represents rotation control at the bit. In summary, the bit state is characterized by the six variables $\xi, \theta, l, h, x$, and $v_{R}$ and is described by six ordinary differential equations.

A discussion of the particular expressions for forces and moments is given in Ref. 14 and is the translation into our own variables of the expressions found in the literature (see, for example, Refs. 15 and 16). We will not debate that subject here.

Simplified model. The hypothesis that input flow rate is always equal to output flow rate implies that:

- The balance equation of fluid mass is no longer necessary.

- Velocity $v_{R}$ is entirely determined by input flow $\left(v_{R} S_{R}=Q_{M}\right)$.

- $h$ is no longer an independent variable, so that the balance of solid mass can be written in the following simplified form:

$\frac{d l}{d t}=S_{C} \frac{d \xi}{d t}-x Q_{M}$

since the quantity $x h$ of cuttings is no longer part of the system.

A convenient simplification of the model is obtained with the assumption that

$x=x\left(\frac{d \xi}{d t}, \frac{d \theta}{d t}, l\right)$

$(\mathrm{A}-8)$ is a given function of the prescribed variables, which corresponds to a direct integration of the relation describing the drag effect of mud on the particles. The preceding remarks lead to a new simplified model, with variables $\xi, \theta, l$, described by the following set of equations:

$$
\begin{aligned}
& \frac{d l}{d t}=S_{C} \frac{d \xi}{d t}-x Q_{M} \\
& M \frac{d^{2} \xi}{d t^{2}}=M g-W_{M}+K_{\xi} \xi_{0}-W_{H}-W_{C}-W_{F}
\end{aligned}
$$

$$
J \frac{d^{2} \theta}{d t^{2}}+V_{\theta} \frac{d \theta}{d t}+K_{\theta} \theta=K_{\theta} \theta_{0}-T_{C}-T_{F}
$$

In this simplified form, it is possible to recognize the coupling between dynamics equations and mass balance equations, introduced by the dependence of weight and torque terms on 1 .

\section{Numerical examples and results}

Partial simplified model with two variables (I and $r$, axial)

$$
\begin{aligned}
& \frac{d l}{d t}=B(t, l, r)=B^{+}(r)-B^{-}(l, r) \\
& \frac{d r}{d t}=W(t, l, r)=W^{+}(t)-W^{-}(l, r)
\end{aligned}
$$

Mathematical forms have been tried, matching as well as possible two kinds of information:

- Empirical evidence derived from tests concerning diamond bits, for which the pump off effect is common.

- Academic and intuitive knowledge based on a quasi-static phenomenological model (Ref. 13), describing hydraulic lift effects in balling conditions for a generic bit model.

Figs. A-1 and A-2 suggest that, for a stabilized level of the command $W^{+}$, several forms of evolution are possible, corresponding to stagnation points that are situated

- On the $r=0$ axis, which corresponds to balling with low weight $(W=1)$, or with excess weight $(W=4,5,6)$.

- On the $l=0$ axis, with $B(r, l)<0$, which corresponds to excess values of hydraulics (perfect cleaning) $(W=2)$.

- On the line $B(r, l)=0$, which corresponds to singular points of the dynamic system, solutions of the system (see Fig. A1 with $\mathrm{W}=3$ )

$$
\begin{aligned}
& B(r, l)=0 \\
& W(t, r, l)=0
\end{aligned}
$$

The command $W^{+}(t)$ changes the position of $W(t, r, l)=0$ in such a way that it influences the evolution of the system. Even though the final weight is the same for the six examples shown in Fig. A-3, one can see that an equilibrium around the 
zone $B(r, l)<0$ is only obtained with a certain rate of weight increase. Sensitivity to initial conditions has also been tested, in the same spirit (Fig. A-4). The results show considerable discrepancies in the evolution of the state for a fixed form of the command.

Full simplified model with three variables (I, $r$, axial, $v$, rotational)

The same kind of simulation can be used to illustrate the response of the simplified model to different indépendant weight $W^{+}$and torque $T^{+}$histories. We notice, as in the preceding model with two variables, that stagnation points of the functions $B, W, T$ play an important role in the evolution of the system and that these points are determined by the global command of the system.

\begin{tabular}{|c|c|c|}
\hline \multicolumn{3}{|c|}{ TABLE 1 - SUMMARY OF TYPE CHARACTERISTICS } \\
\hline TYPE I & TYPE II & TYPE III \\
\hline $\begin{array}{c}T_{D} \text { not significantly affected } \\
\text { by } R_{D} \text { values }\end{array}$ & \multicolumn{2}{|c|}{$\begin{array}{c}\text { Strong dependency of } T_{D} \text { with } R_{D} \text { values; } \\
\text { strong departures from mean }\end{array}$} \\
\hline $\begin{array}{c}\mathrm{T}_{\mathrm{D}} \text { average values } \\
\text { around } 0.10-0.15\end{array}$ & $\begin{array}{c}\text { High } \mathrm{T}_{\mathrm{D}}(0.25) \\
\text { Low } \mathrm{R}_{\mathrm{D}}(0.05) \\
\text { Low WOB }\end{array}$ & $\begin{array}{c}\text { Low } \mathrm{T}_{\mathrm{D}}(0.05) \\
\text { Low } \mathrm{R}_{\mathrm{D}}(0.05) \\
\text { High WOB }\end{array}$ \\
\hline
\end{tabular}
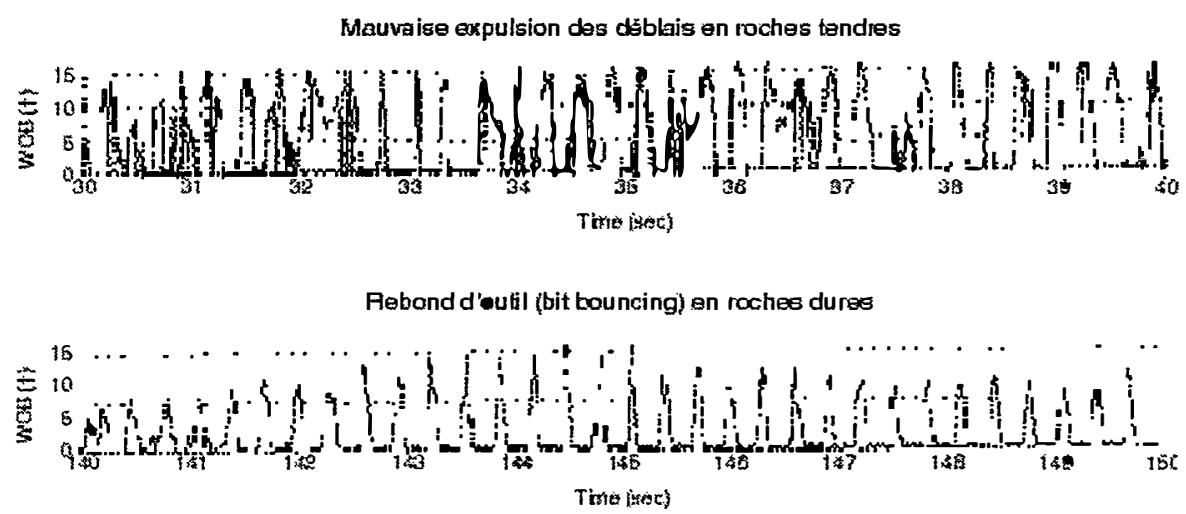

Fig. 1 - Two examples of axial dynamics obtained with Trafor data at the bit (courtesy of J. Guesnon) Upper part: chaotic axial dynamics in soft rock drilling Bottom part: bit bouncing with a three-lobed pattern in hard rock drilling 

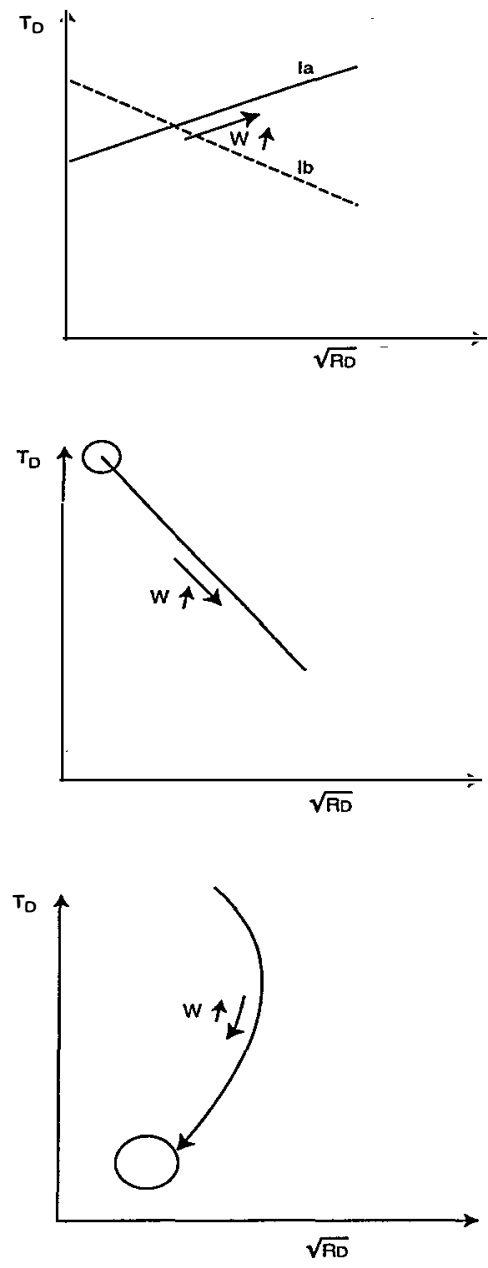

Type la : $\sqrt{A_{D}}$ and To both increasing with $W$

Type lb: $\sqrt{R_{0}}$ increasing with $W$

$T_{D}$ slightly decreasing with $W$

Type II
(balting with too low weight) $\sqrt{R_{0}}$ increasing with $W$ $T_{D}$ strongly decreasing with $W$
$T_{0}$

Balling with excess weight

Balling with excess weight
$\sqrt[R D]{ }$ and $T_{O}$ both decreasing with increasing $W$

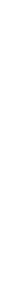

Fig. 2 - The three typical regimes, according to mud hydraulics cleaning conditions.

Fig. 2a - Normal case (types Ia and Ib)

Fig. 2b - Balling with too low weight (type II)

Fig. 2c - Balling with excess weight (type III)

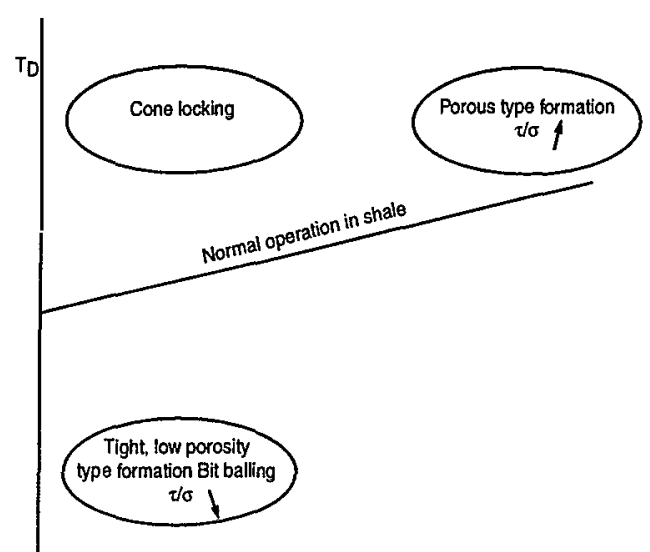

$\sqrt{\mathrm{RD}}$

Fig. 3 - Dimensionless torque, $T_{D}$ as a function of the normalized rate of penetration, $R_{D}$, (Ref. 9). 


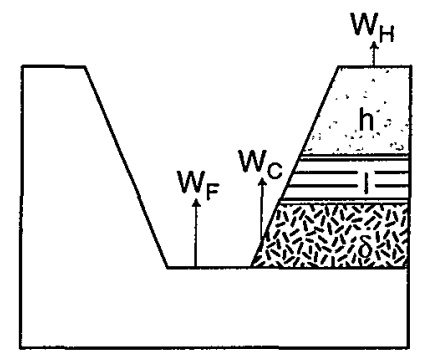

Fig. 4 -Conceptual view of drilling system with :

$$
\text { balance pf mass } \mathrm{B}=\mathrm{B}^{+}-\mathrm{B}^{-}
$$

input flux $B^{+}: \quad \delta$ : equivalent depth of cut $d \xi / d \theta$

output flux $\mathrm{b}^{-}: \quad 1:$ crushed rock material volume (cutting bed)

$h$ : volume of current mud and cutting

reaction forces $\mathrm{W}$ -

vertical forces equilibrium $\mathrm{W}=\mathrm{W}^{+}-\mathrm{W}^{-}$

$\mathrm{W}_{\mathrm{C}}$ : Vertical component of cutting forces

$\mathrm{W}_{\mathrm{F}}$ : Vertical component of friction forces

$\mathrm{W}_{\mathrm{H}}$ : Hydraulic lift-off

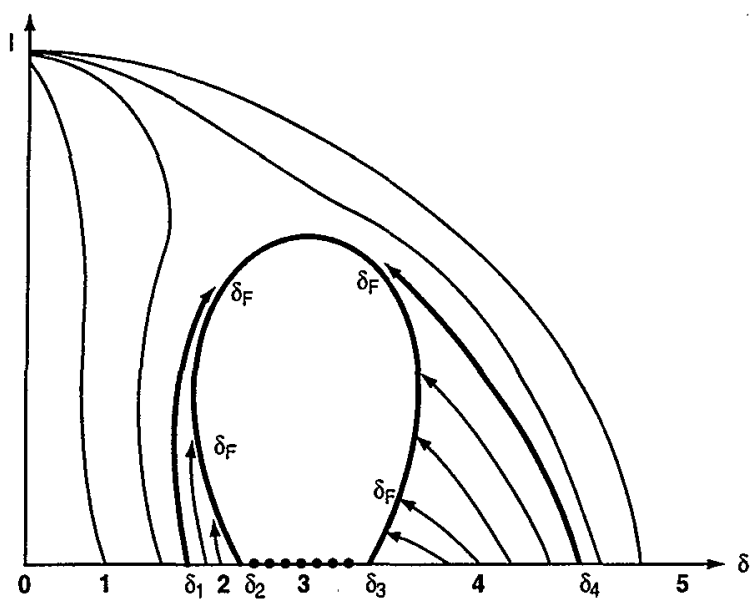

Fig. 5a - Quasi-static model CUTCLEAN . State evolution from particular initial conditions $\left(\delta=\delta_{l}, l=0\right)$; display of five regimes, depending on initial value $\delta_{I}$

- (1) and (5) are balling regimes, corresponding to an excess rate of rock production over hydraulic cleaning possibilities.

- (3) is characteristic of perfect cleaning conditions, with no evolution of the figurative point.

- (2) and (4) are regimes which result from dynamic equilibrium between production and cleaning. 


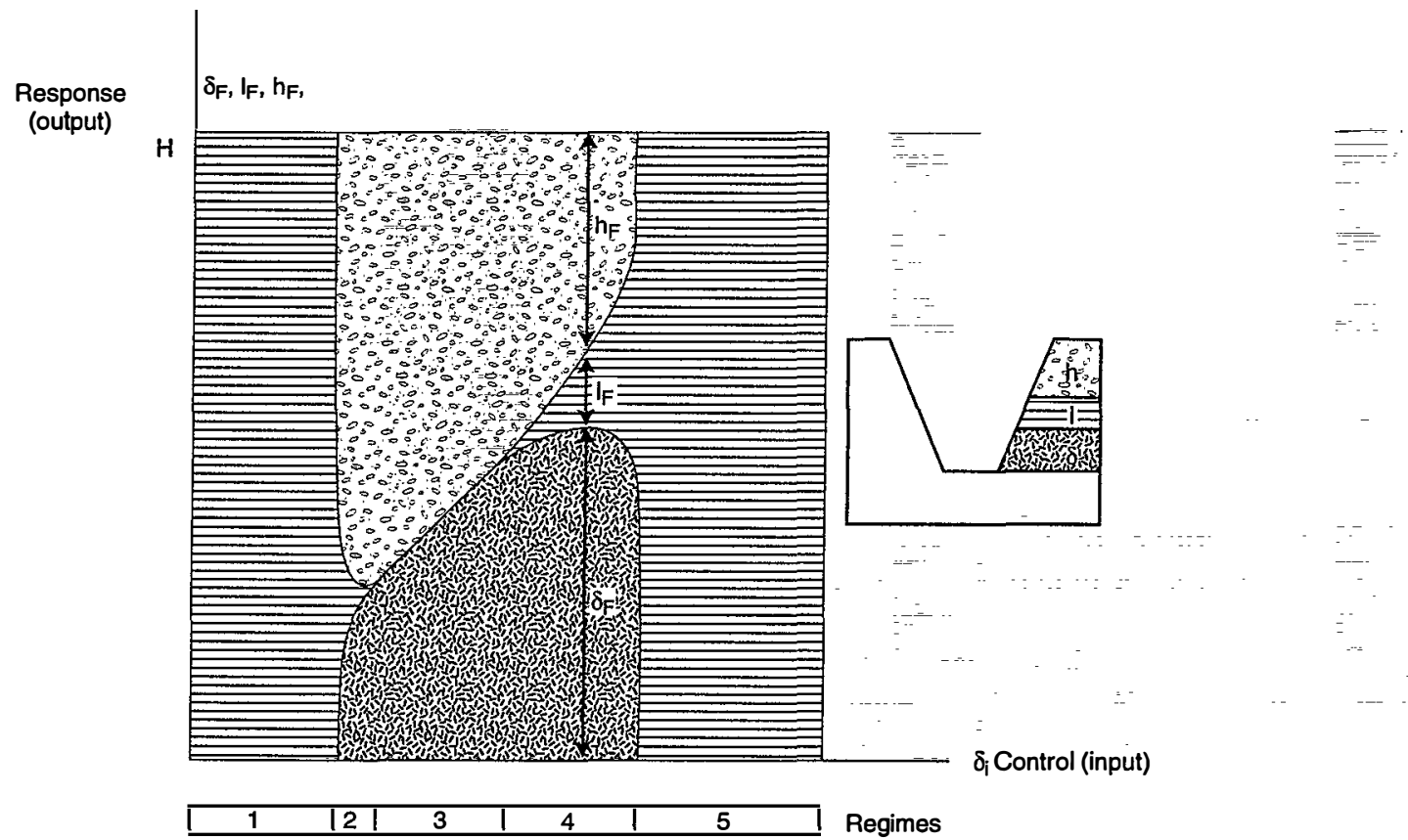

Fig.5b - Quasi-static model CUTCLEAN . Full response $\delta_{F}, l_{F}$ after transient, as a function of input, initial depth of cut.

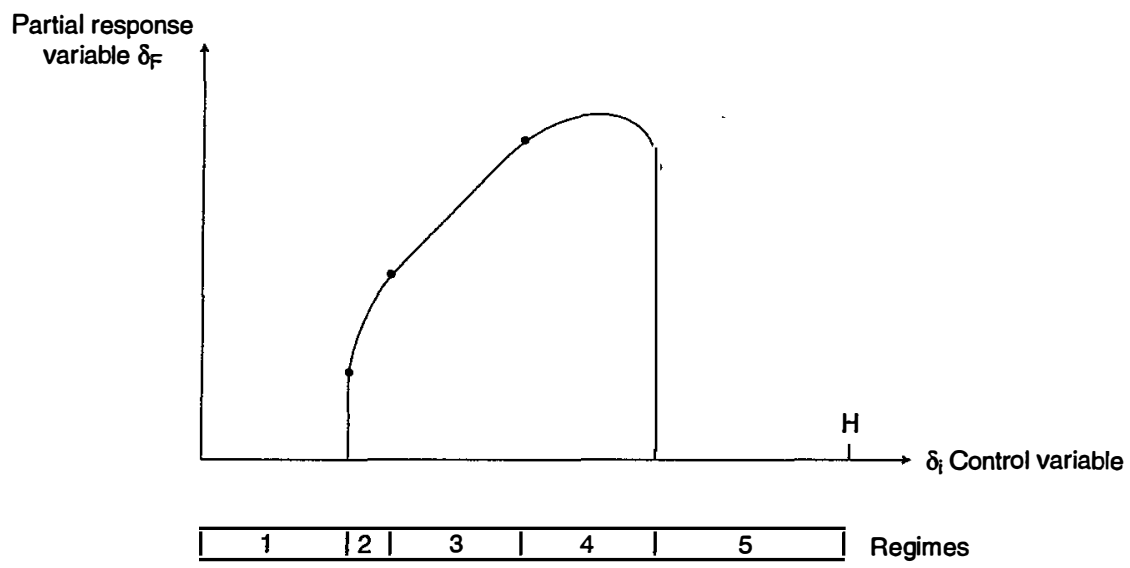

Fig. 5c - Quasi-static model CUTCLEAN . Partial response $\delta_{F}$, stabilized depth of cut after transient, as a function of input $\delta_{l}$, initial depth of cut $\delta_{l}$ reflects imposed weight on bit $\delta_{F}$ reflects the ratio rate of penetration over rotary speed.

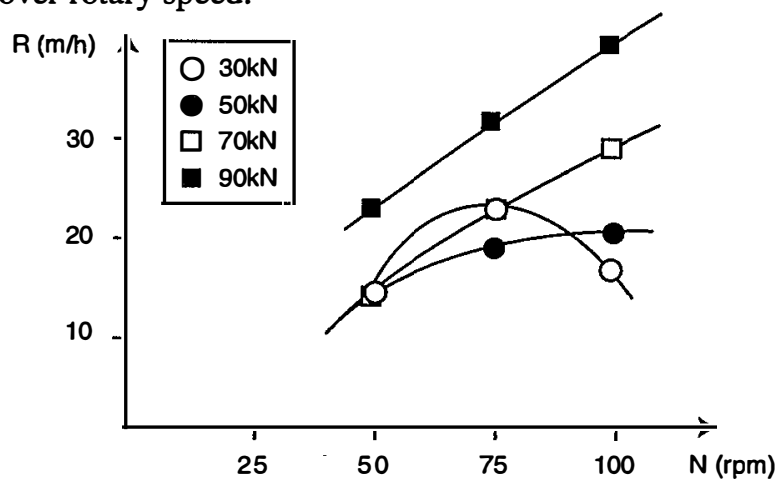

Fig. 6 - Average response (rate of penetration) as a function of rotary speed, $N$, for given weight, $\mathrm{W}$, for stabilized sequences. 

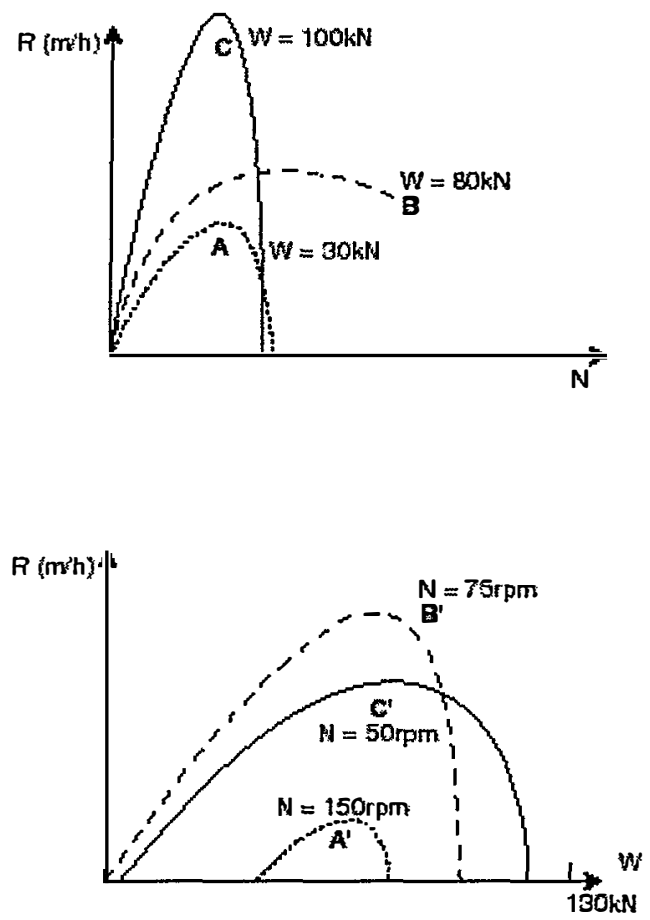

Fig. 7 - Determining the zone of maximal efficiency. The sensitivity of the response, $R$ (rate of penetration), to partial control variables, either $\mathrm{W}$ or $\mathrm{N}$, the other factor remaining constant. Range of use of bits for the commands weight and rotary speed.

Fig. 7a - When choice of W precedes that of $N$.

Fig. 7b - When choice of $\mathrm{N}$ precedes that of $\mathrm{W}$.

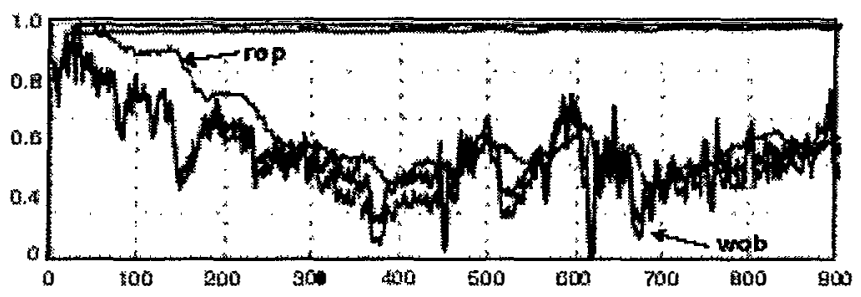

Fig. 8 - Field data exhibiting balling tendencies (low rate of penetration) with insufficient weight on bit. case 870 , sequence $\mathrm{A}$

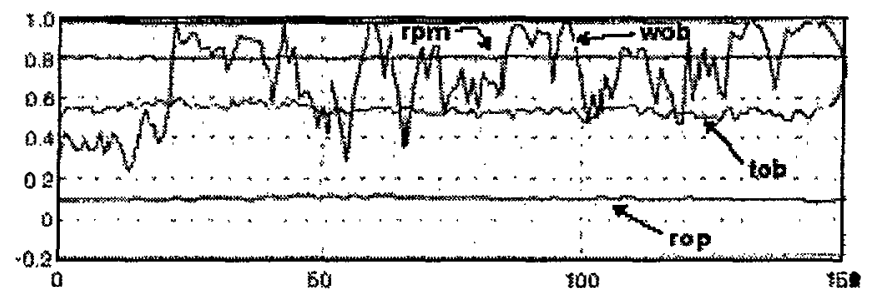

Fig. 9 - Field data exhibiting balling tendencies (low rate of penetration) with excess weight on bit. Case 867 , sequence A 

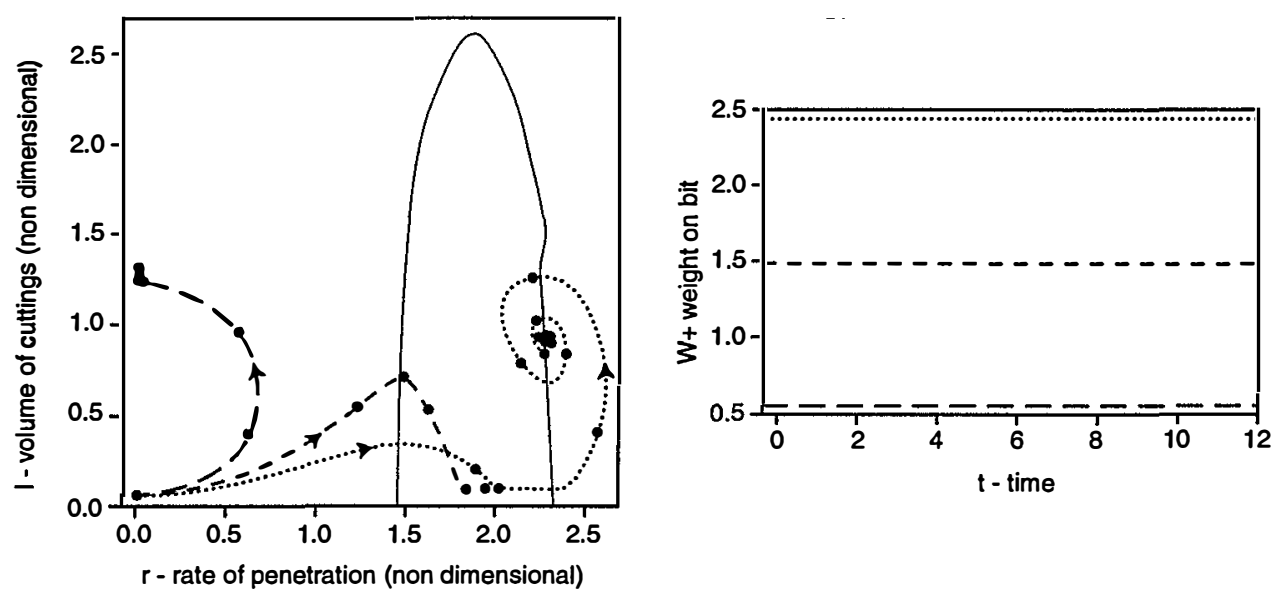

Fig. A-1 Evolution of the system for a constant weight, W (lower weights).
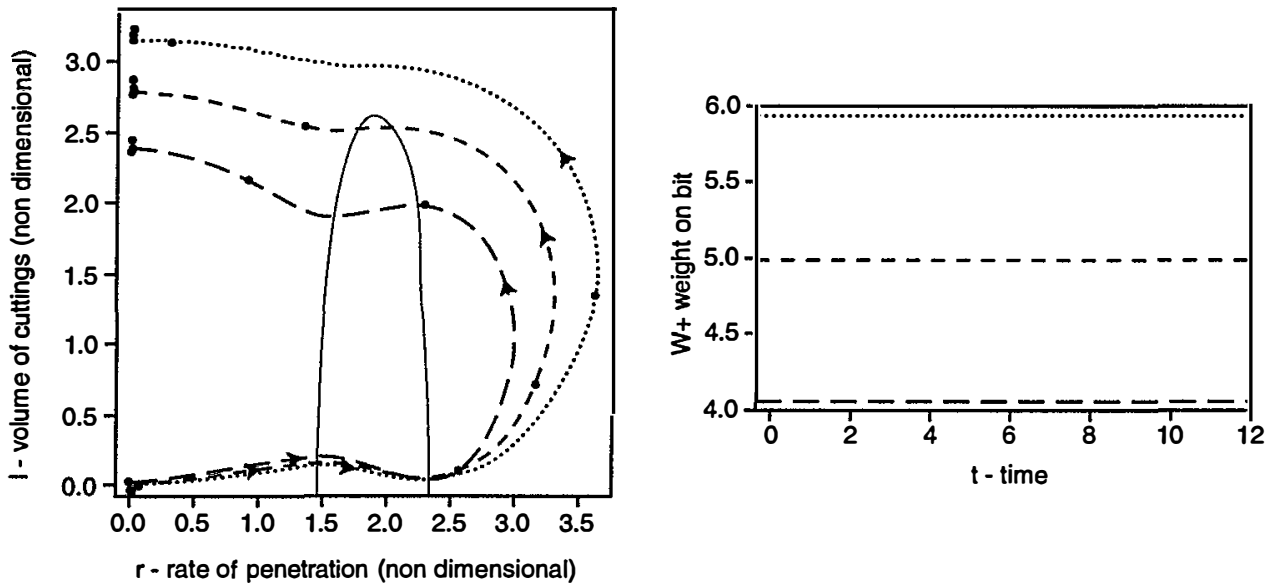

Fig. A-2 Evolution of the system for a constant weight, W (higher weights). 

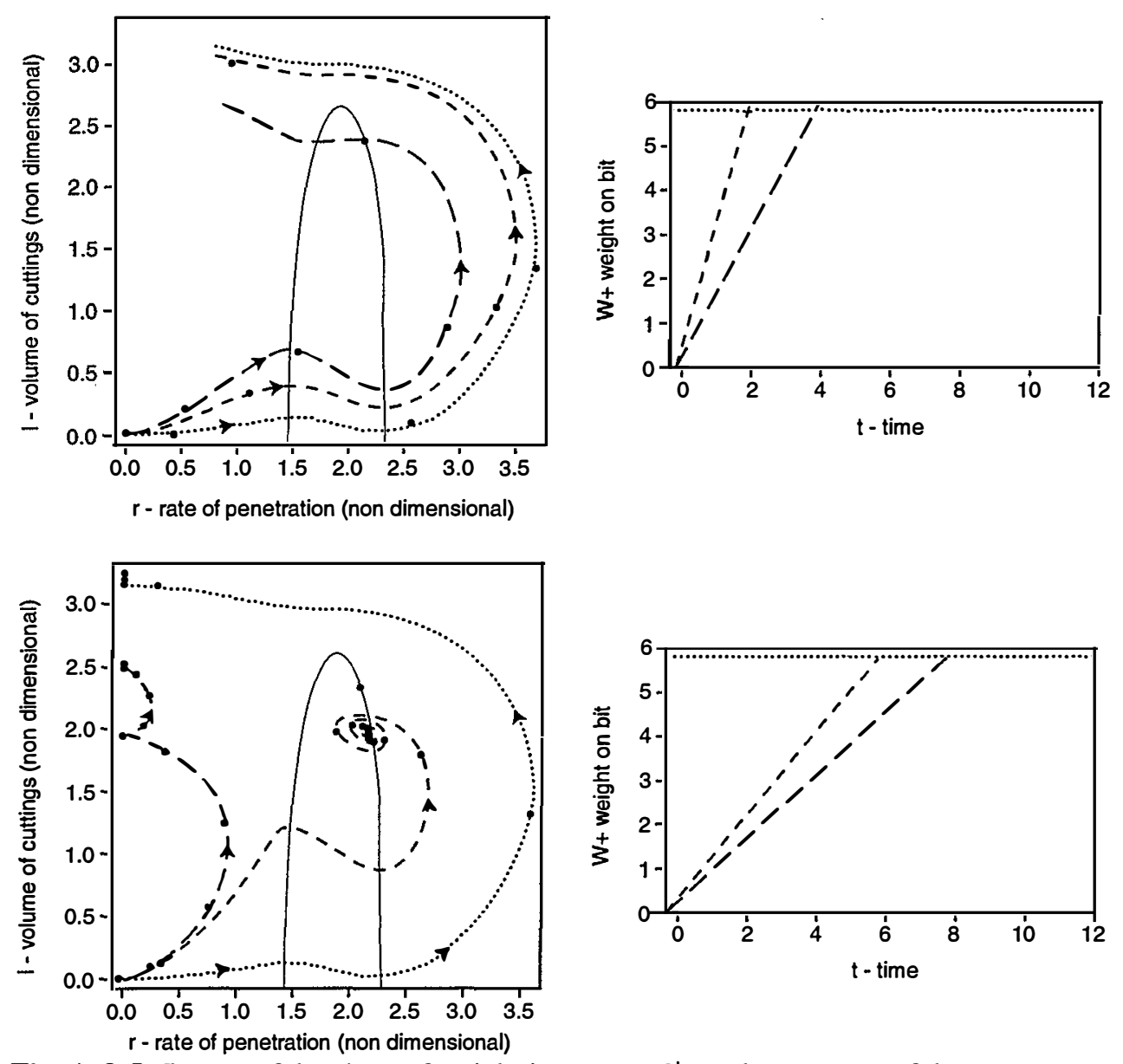

Fig. A-3 Influence of the slope of weight increase, $\mathrm{W}^{+,}$on the response of the system. 

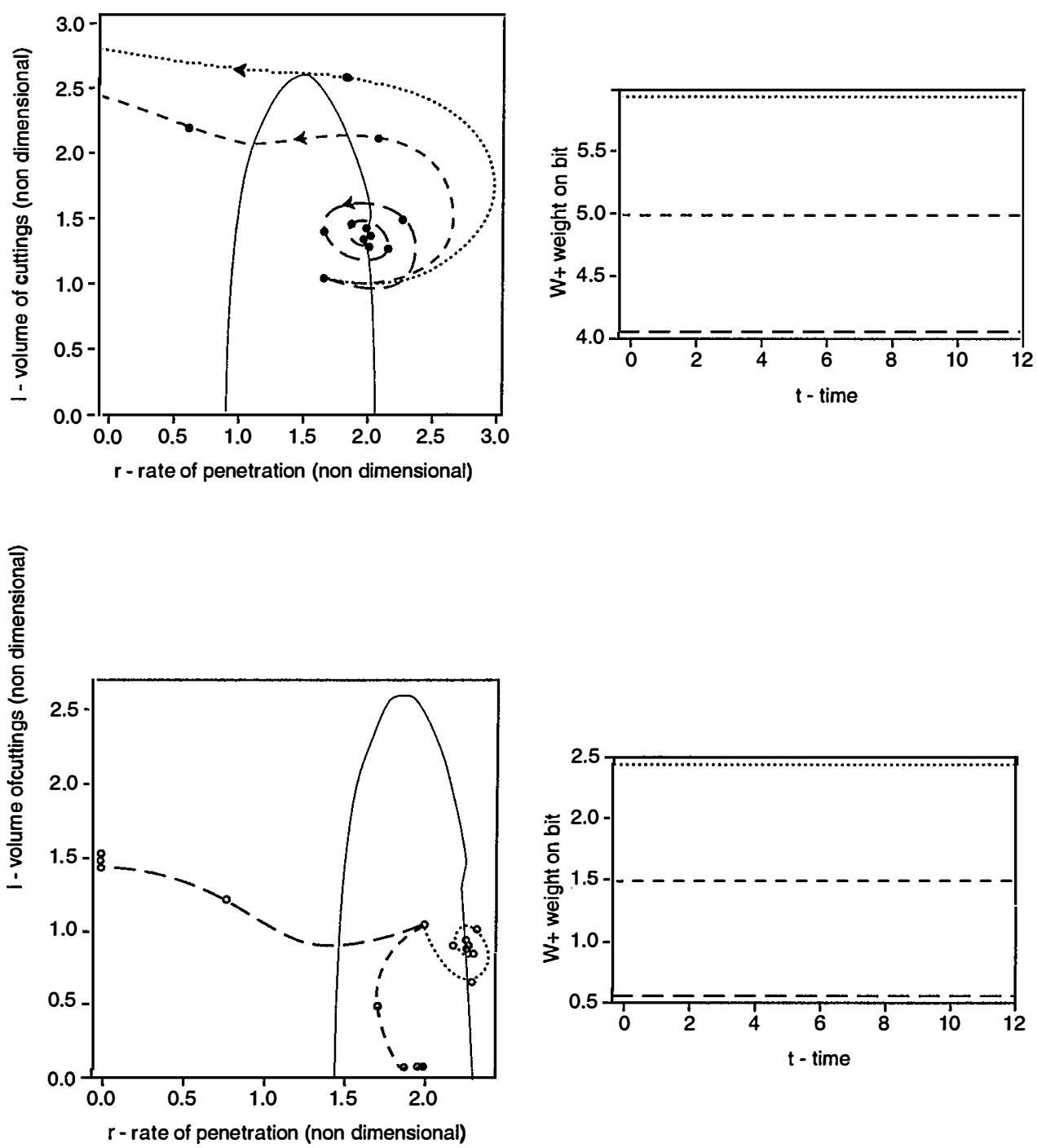

Fig. A-4 Sensitivity to initial conditions. 